\title{
PÁGINAS DE UMA AGENDA: \\ O AGENDAMENTO MIDIÁTICO \\ PARA A COPA DE 2014
}

\author{
MS. HUDSON PABLO DE OLIVEIRA BEZERRA \\ Rede Municipal de Ensino de Portalegre, Prefeitura Municipal de \\ Portalegre; Rede Estadual de Ensino do Rio Grande do Norte, \\ Governo do Estado do Rio Grande do Norte \\ (Portalegre - Rio Grande do Norte - Brasil) \\ E-mail: hpobezerra@gmail.com
}

\section{MS. BERTULINO JOSÉ DE SOUZA}

Departamento de Educação Física, Universidade do Estado do Rio Grande do Norte (Natal - Rio Grande do Norte - Brasil)

bertulinosouza@uern.br

\begin{abstract}
RESUMO
No cenário brasileiro em que o país conquista o direito de sediar os dois maiores eventos de competição esportiva, a Copa do Mundo de Futebol em 2014 e as Olimpíadas em 2016, a relação da mídia com o esporte certamente será intensificada e, dessa forma, devemos estar atentos para não sermos apenas consumidores passivos das informações midiáticas. Portanto, na busca por compreensões sobre essa relação, objetivamos neste trabalho refletir sobre o agendamento midiático para a Copa do Mundo de Futebol de 20 I 4, assim, a pesquisa investigou os telejornais Esporte Fantástico (Rede Record) e Esporte Espetacular (Rede Globo) durante o mês de abril de 2010.
\end{abstract}

PALAVRAS-CHAVE: Mídia; Copa do Mundo de 20I4; agendamento; Educação Física. 
Penetrar nas veredas que nos conduzem a discussões sobre esporte significa estar entregue a um percurso construído entre o fascínio e a dúvida. Este fascínio é encontrado na capacidade do esporte de promover uma transcendência dos sujeitos da realidade para um "mundo" tecido no domínio das emoções, e, de forma oposta, provoca dúvidas pelo poder de satisfação e dominação que exerce nas relações sociais e na vida das pessoas.

No contexto atual, as manifestações das práticas esportivas marcadas pela massificação dominam um amplo espaço da vida social e cultural das pessoas. Através de diferentes formas e com objetivos distintos elas adentraram e se fixaram no imaginário popular, passando a influenciar as relações sociais dos diferentes grupos populacionais e instituições (BRACHT, 2009). Entretanto, destacamos que o esporte é hegemonicamente consumido através do esporte de alto rendimento nas competições esportivas.

Nestes eventos, a ampla dimensão e a representatividade social fazem com que sejam depositados múltiplos interesses na organização e participação. Diante disto, a mídia destacar-se-á por utilizar o esporte como conteúdo de informação e entretenimento, bem como para ludibriar, alienar e aprisionar a população em seus interesses.

No entanto, elucidamos que uma das instituições da mídia ganha destaque nesse processo, a televisão. É oportuno evidenciar que a parceria da televisão com o esporte não é recente, todavia decorre de um processo de longa data que se modelou de acordo com as influências históricas, culturais, sociais, políticas e econômicas pelas quais passaram (BETTI, 1997).

A compreensão dos interesses estabelecidos na relação da televisão com o esporte é importante para uma atuação crítica e emancipada diante das informações midiáticas. Esse fato merece maior atenção no atual cenário brasileiro em virtude do país ter conquistado o direito de sediar as duas maiores competições esportivas do mundo: a Copa do Mundo de Futebol em 2014 e as Olimpíadas em 2016.

Com a conquista do direito de organizar e sediar estes eventos, muitos investimentos foram e serão realizados, fato que demanda uma atenção de esferas sociais como os espaços acadêmicos enquanto problematizadores dos diálogos sociais mais emergentes. Entretanto, diante da proximidade da realização da Copa do Mundo de Futebol em 2014 em relação às Olimpíadas em 20 I 6, direcionaremos as reflexões para este evento.

Mesmo com uma distância cronológica considerável, as reflexões sobre a Copa de 2014 se devem ao fato de buscarem dedicar um olhar especial para o 
cenário brasileiro e os investimentos que nele serão realizados, quer sejam ou não relacionados à organização deste evento.

Conforme anunciam os discursos veiculados nos espaços midiáticos, a Copa de 2014 já começou. A organização prévia e divulgação nos espaços midiáticos colocam em pauta assuntos que devem ser discutidos nos espaços sociais antes da realização do evento. Isto configura nos estudos das comunicações uma teoria denominada de agendamento, que será posteriormente discutida com maior profundidade (MEZZAROBA, 2009).

Dessa forma, objetivamos neste trabalho refletir sobre o processo de agendamento midiático para a Copa do Mundo de Futebol de 2014 realizado pelos telejornais esportivos Esporte Fantástico, da emissora Rede Record, e Esporte Espetacular, da emissora Rede Globo. Para tanto, utilizamos metodologicamente uma pesquisa descritiva de abordagem qualitativa (SEABRA, 200I). Os dados para análise foram obtidos a partir de gravações de fitas em vídeo cassete e download nos sites dos referidos telejornais durante o mês de abril de 2010.

Portanto, a partir dos resultados e das discussões realizadas sobre estes dados, refletiremos acerca da relação dos esportes com as instituições midiáticas, especialmente durante a realização dos megaeventos esportivos. Estas reflexões oportunizarão pensar o processo de formação e a atuação dos profissionais de Educação Física no tratamento das informações veiculadas pela mídia sobre os assuntos esportivos.

\section{ESPORTE E MÍDIA: EM QUE SE PAUTA ESSA RELAÇÃO?}

Diante da relação estabelecida entre a mídia e as práticas esportivas na atualidade, torna-se necessário o desenvolvimento de processos investigativos que se propunham a compreender os elementos conectivos dessa relação. Sobre as características da mídia, Gastaldo (2009, p. 353) faz os seguintes esclarecimentos:

\footnotetext{
Em termos do senso comum, se entende por "mídia" os "meios de comunicação de massa" [...], ou seja, os veículos de comunicação, tomadas como dimensão tecnológica, que, a partir da produção centralizada, veiculam seus produtos de modo "massificado", isto é, a um público numeroso e indistinto, sem levar em conta a individualidade de cada um dos participantes deste público.
}

No entendimento apresentado por Gastaldo (2009) a mídia seria o instrumento responsável por transmitir ou mediar informações entre "produtores" e "receptores". Diante desta compreensão, a mídia enquanto veículo de formação e informação não é neutra. Há em sua atuação uma variedade de intencionalidades 
nem sempre explícitas, visto que é "veículo" e será guiado a partir dos interesses de seus condutores.

Todavia, os processos de mediação dos assuntos esportivos possuem características que lhes permitem se diferenciar das demais categorias de informação e entretenimento veiculados pela mídia. Na atualidade, diversas são as estratégias de mediação que utilizam o conteúdo esportivo para a veiculação de informações, na mesma proporção, encontramos uma quantidade considerável de pessoas que consomem, ou recebem as informações midiatizadas sobre esse fenômeno social. No entanto, é importante compreender que "o uso do esporte pela mídia provoca um impacto sobre a maneira como percebemos e praticamos o esporte" (BETTI, 1997, p. I).

O apontamento realizado por Betti ( 1997) reflete sobre a relação do esporte com a mídia, visto que o esporte, quando "usado" pela mídia, recebe adequações e conceitos que são atribuídos pelos produtores das informações de forma a enquadrá-lo nos objetivos das instituições midiáticas, ocultando na maioria das vezes suas características iniciais, bem como atribuindo outras que não são encontradas em sua prática.

Essencialmente, neste processo de mediação das informações esportivas o meio televisivo ganha destaque. Em sua grade de programação são evidenciadas, constantemente, marcas das práticas esportivas através de diferentes programas, dentre elas destacamos as marcas firmadas pelos telejornais esportivos. Este gênero de programa televisivo vem cada vez mais ganhando destaque nas diferentes emissoras da televisão brasileira.

Sobre esta modalidade de informação do meio televisivo, ou seja, os telejornais esportivos, Silva e Marchi Junior (2009, p. I I) destacam que é:

\footnotetext{
Uma fusão entre jornalismo e televisão que possui uma forma própria de informar. Ao mesmo tempo em que agrupa fontes, notícias e seleciona conteúdos, como o jornalismo, o telejornalismo esportivo, detém algumas especificidades que outros gêneros do jornalismo não podem recorrer, como um arquivo de imagens, ou a técnica de mediação orientada por um profissional que não somente transmite a mensagem, mas algumas vezes oferece uma leitura da notícia.
}

Contudo, essa fusão tem algumas implicações, visto que os assuntos esportivos veiculados por esse gênero de jornalismo exageram no sentimento e emoção, e deixam a desejar na coerência e objetividade, como forma de apreender para seus espaços uma quantidade maior de pessoas que se envolvem sem que antes façam uma análise crítica das informações que estão recebendo.

De acordo com Souza (2006, p. 6) "por mobilizar um número maior de sentidos, a televisão está sempre à procura daquilo que desperta emoção nas pessoas". Quanto 
aos espaços do telejornalismo, "esta procura se manifesta no caráter melodramático emprestado às reportagens”.

Diante destas características, destacamos que diversas foram as mudanças ocorridas nas estruturas midiáticas para utilização dos conteúdos esportivos em suas transmissões, entretanto, a recíproca também é verdadeira. Como cita Costa (2007, p. 8) "se por um lado os meios de comunicação se especializaram para adentrar o universo do esporte e colocá-lo em sua pauta, por sua parte o esporte fez sérias concessões na sua parte atlética e competitiva para atender os interesses midiáticos". Para tanto, é perceptível que não só a mídia, em especial a televisão, realizou modificações para se adequar ao esporte, mas esse também realizou inúmeras modificações para servir aos interesses das instituições midiáticas. Temos assim uma troca mútua de interesses.

Na opinião de Alves Júnior (2008, p. I I ) "o casamento entre a televisão e o esporte tem se mostrado bastante rentável, notadamente para o desenvolvimento do esporte espetáculo e, consequentemente, para as emissoras de televisão e imprensas a elas associadas". É diante dessa poderosa estratégia de venda e comercialização de produtos que a mídia tem a cada dia estreitado os vínculos com os assuntos esportivos.

Podemos compreender a televisão como um dos meios de comunicação de maior expressividade no cenário brasileiro. Como afirmam Rocha e Aucar (201 I, p. 56) "até hoje nenhum outro veículo movimenta mais audiência das massas do que a televisão". Esta é utilizada como fonte inesgotável de formação e informação, por outro lado é importante que também a reconheçamos como fonte de dominação e alienação.

A televisão, para Betti (1997, p. 4I), apresenta:

Uma realidade já pronta, que não atinge a criatividade do receptor; acarretando a perda do direito de escolha e da livre concentração, e estabelece com o espectador uma relação guiada por interesses mercadológicos. [...] A televisão impõe um novo imaginário.

Complementando, Betti (1997, p. 4I) argumenta que "a linguagem-imagem da televisão compõem-se de estereótipos que despertam o inconsciente do telespectador, e assim demonstram como devem comportar-se de acordo com os desejos do sistema". Esta os prende em estruturas que são imperceptíveis, porém respeitáveis, de forma que não oportunize autonomia crítica para refletir sobre o que é recebido. Todavia, é necessário reconhecer pontos de resistências de alguns telespectadores às informações recebidas, pois estes já possuem em si uma bagagem que lhes permitem inferir sentido ao que chega através da mídia.

Quanto à padronização de comportamentos implantados pela televisão, Costa (2007, p. 9) fala que "o fascínio que as imagens exercem nas pessoas convida-os a 
adentrar no mundo performático da mídia. A realidade dos meios de comunicação, de certa forma, passa a ser a realidade do cotidiano". Com essas características a televisão funcionaria como um vetor determinante de comportamentos, especialmente pelo grande fascínio que provoca nas pessoas levando-as muitas vezes a um estado de falsa consciência sobre a "realidade apresentada" e a "realidade vivida".

Quando associamos o fascínio provocado pela televisão e aquele provocado pelo esporte moderno, especialmente o esporte na forma de espetáculo das competições de prestígio nacional e internacional, estamos diante de um poderoso arsenal de entretenimento e alienação para população.

Refletindo sobre esta parceria, Silva e Marchi Júnior (2009, p. 7) argumentam que "através do poder de suscitar emoções, a televisão encontra nos eventos esportivos momento bastante adequado para explorar o imaginário do indivíduo". Ou seja, esta utiliza deste espaço onde o racionalismo está marginalizado para introduzir novos valores e significados ao telespectador.

Frente a estas considerações, torna-se necessário reconhecer e refletir que, com as transmissões dos eventos esportivos, a televisão tem levado os telespectadores a um estado de alienação que é caracterizado essencialmente pela ilusão de que ao "participarem" dessas transmissões eles se tornarão esportistas ou autoridades nos assuntos do esporte. Todavia, pensando a estrutura da mediação televisiva, verifica-se que a participação destes nestas transmissões ocorre apenas como receptores, visto que todo conteúdo transmitido é previamente elaborado. Entretanto, assiste-se na atualidade, em alguns espaços da mediação esportiva, uma tentativa de interação entre os produtores e os receptores das informações, tais como os comentários que podem ser feitos durante as partidas de futebol via e-mail.

Embora a capacidade de interferência da televisão nos telespectadores pareça somente negativa, essa também desperta a capacidade de argumentação quanto a assuntos debatidos no meio esportivo. No entanto, é necessário problematizar as informações de forma crítica e reflexiva para que os receptores consigam apreender os detalhes da relação entre o esporte e a mídia.

Destacamos ainda que a atuação da televisão na transmissão do esporte traz, dentre outras consequências, a fragmentação e a distorção das práticas esportivas. Para Betti (1997, p. 37) esse fato acontece por que:

A televisão seleciona imagens esportivas e as interpreta para nós, propõem um certo "modelo" do que é "esporte" e "ser esportista". Mas, sobretudo, fornece ao telespectador a ilusão de estar em contato perceptivo direto com a realidade, "como se estivesse olhando através de uma janela de vidro".

Essa "janela de vidro" é acessada facilmente pela população através de seus lares, todavia, "a imagem que o telespectador vê produz apenas certas condições 
de percepção do original, uma reprodução que passa pela limitação dos próprios códigos televisivos. [...] Ele só verá o que a câmera lhe mostrar" (BETTI, I 997, p. 38).

Com as técnicas de som, imagem, efeitos especiais, dentre outras, adotadas pelos gêneros televisivos na transmissão dos eventos esportivos, Pires (2006, p. 4) conclui que "estas são condições tecnológicas que visam compensar a substituição da experiência subjetivamente vivida pela mediação televisiva". Isto é, uma busca por compensar as faltas que as imagens da televisão têm em relação ao contexto das práticas esportivas, além de trazer elementos que não podem ser encontrados na realidade.

Dessa forma, segundo Alves Júnior (2008, p. 17), "com a aplicação de novas tecnologias de comunicação no campo da transmissão eletrônica do esporte, o espectador, presente no local da disputa, e o telespectador, que assiste a televisão, consomem espetáculos diferentes". Embora se assista ao mesmo espetáculo, os meios pelos quais estes são apreciados nos deixam diante de situações diferentes. $\mathrm{Na}$ apreciação da realidade os sujeitos são responsáveis pelas escolhas do que querem ver, na transmissão midiática são seres passivos que na maioria das vezes apenas recebem as informações pré-digeridas.

Com isso, a figura do telespectador desperta questionamentos e nos coloca diante de dois perfis. Para Alves Junior (2008, p. 17) "ele pode ser em mero telespectador passivo, consumidor de informações e produtos, mas também pode ser agente crítico capaz de filtrar e interpretar criticamente o que lhe é transmitido". Seguramente a televisão se interessa mais pelas características do primeiro tipo, pois com esse perfil de telespectador suas informações são rapidamente assimiladas sem maiores questionamentos.

Segundo Betti (1997), o telespectador que consome as transmissões esportivas é impedido de realizar uma reflexão crítica, bem como de localizar os sentidos ocultos e as intencionalidades das transmissões por consequência da fragmentação, da velocidade, da reconstrução da realidade, do rebaixamento das exigências intelectuais e do impacto direto sobre o plano emocional causado pelas imagens.

A falta de conhecimento e de uma formação crítica impede que alguns telespectadores se "libertem" das emoções para agir através de posicionamentos racionais. Tornam-se assim, "escravos" dos produtores das informações. Como diz Marcondes Filho (2002, p. 19) "uma sociedade sem crítica é uma sociedade morta: o componente humano sede lugar às relações maquínicas, aos processos tecnológicos marcados por inteligências artificiais e estúpidas".

Portanto, qual seria a solução para mudar este perfil de telespectador? Que estratégias deveriam ser utilizadas? Quais as consequências desta mudança? Certamente são questionamentos de difíceis respostas, porém para respondê-los as relações entre a mídia e o esporte devem ser problematizadas. 
Neste estudo, a problematização desta relação acontece diante de um "elemento" de grande importância para a população brasileira, a realização de Copas do Mundo de Futebol. Segundo Gastaldo (2002, p. 22), "uma Copa do Mundo representa para os brasileiros o verdadeiro momento ritual de celebrar a nacionalidade". É através do fascínio provocado por essa competição, e pela confiança que depositamos na seleção nacional "que temos nos pensado enquanto nação e povo" (BITENCOURT, 2009, p. 174).

Diante disso, questiona-se como será constituída a relação prévia da mídia com a Copa do Mundo de Futebol em 2014 que será sediada no Brasil? Direcionaremos os olhares ao processo de agendamento que a Televisão, especialmente os telejornais esportivos, tem efetivado para a realização desse megaevento.

\section{ATENÇÃO! PROCURA-SE PÁGINAS DE UMA AGENDA.}

O presente estudo se apropria da teoria do agendamento para pensar a relação do esporte com a mídia, especialmente da televisão com a Copa do Mundo de Futebol de 20 I 4 que será sediada pelo Brasil. De acordo com Mezzaroba (2009, p. 3) "o conceito de agendamento é apenas uma tradução do agenda-setting no inglês", que resumidamente significa o processo de discussão e debate organizado pela mídia antes da realização de um evento.

Tomando como base os estudos de Baibich (2007, p. 15), o agenda-setting, ou também, Teoria do Agendamento, "surgiu de um estudo de Maxwell McCombs, em 1968". Nesse estudo, McCombs "analisou os efeitos dos meios de comunicação de massa em eleitores indecisos" e chegou à conclusão de que "os acontecimentos e questões enfatizadas pela mídia entram na agenda de discussões do público que acompanha os meios de comunicação. A mídia determina os assuntos que serão tratados por seu público".

Baibich (2007, p. 16) também argumenta que:

A mídia serve segundo esta teoria, como meio pelo qual o público constrói seu conjunto de assuntos de interesse. A teoria do agendamento não fala em uma influência direta da mídia na opinião do público, mas ela tem o papel decisivo de definir quais os tópicos merecem opinião e interesse de quem está atento aos veículos de comunicação.

Assim, de acordo com essa teoria, a mídia seria responsável pela construção da pauta de temas para o debate público, apresentando o que lhe desperta interesse e escondendo o que não lhe interessa. Ainda, "além de exercer este papel de 'mestre-de-cerimônias', e determinar os problemas que serão debatidos na sociedade, a mídia também determina o nível de importância que cada tema adquire neste debate" (BAIBICH, 2007, p. 16). 
O agendamento midiático seria assim um processo de longo prazo, que aos poucos e continuamente oportunizaria o debate para a formação de opiniões e a preparação para a realização dos eventos, no caso específico deste trabalho, a Copa do Mundo de Futebol de 2014.

Com base em Mezzaroba e Pires (2009, p. 3) compreendemos o agendamento como:

Um processo relacional entre a agenda jornalística e a agenda pública, em que há uma tentativa de alguns grupos (financeiros, econômicos, políticos e a própria mídia) em pautar termos e assuntos de seu interesse na esfera social e colocar, desta maneira, sua(s) opinião(ões) com o objetivo de torná-la(s) hegemônica(s). O agendamento, portanto, é sempre exercido pela mídia, veículo que opera tais interesses, mas tem uma relação de interação com a opinião pública, assim como com grupos privados ou da esfera pública, fazendo com que, em sua operacionalização, vários campos se cruzem.

Com base neste entendimento do processo de agendamento, propomos analisar como os telejornais esportivos estão agendando a Copa de 2014 e quais as intenções desse processo. A pesquisa aconteceu durante o mês de abril de 2010 e teve como espaço de investigação os telejornais esportivos: Esporte Fantástico transmitido aos sábados pela emissora Rede Record e Esporte Espetacular transmitido aos domingos pela emissora Rede Globo.

Na coleta do material de análise, utilizamos a gravação de fitas através de vídeo cassete e das reportagens disponibilizadas para download nos sites dos programas Esporte Fantástico (http://www.rederecord.com.br/programas/esportefantastico/_home.asp) e Esporte Espetacular (http://globoesporte.globo.com/programas/ esporte-espetacular/).

No material coletado foram apresentadas 129 reportagens. Para a análise, dividimos e classificamos inicialmente as reportagens dentro de categorias (grupos estabelecidos para aglutinar reportagens sobre a mesma temática). Nestas reportagens foram citadas inúmeras modalidades esportivas, entretanto, uma recebeu maior destaque, o futebol. Com 79 reportagens essa categoria foi reclassificada em subcategorias como: clubes de futebol, onde foram apresentadas reportagens sobre os clubes de futebol brasileiro tais como: Portuguesa Santista, São Paulo, Santo André, Botafogo, Corinthians, Palmeiras e Santos, sendo que esta última obteve o maior número de reportagens em vista do bom desempenho acompanhado nas competições realizadas no período das gravações.

Além desta, obtivemos ainda subcategorias referentes à: futebol inclusão e superação; mulher e futebol; campeonatos estaduais; futebol internacional; locutores de futebol; futebol e lazer; humor e futebol; história do futebol; mascotes do futebol; 
futebol nas academias; escândalos, polêmicas e fraudes; personagens e fatos marcantes; e, Copa do Mundo de Futebol de 20 10. Esta última obteve destaque dentre as demais subcategorias do futebol em vista da proximidade da realização do evento em 2010 na África do Sul, e abordou assuntos como: opinião popular sobre a convocação dos jogadores para a Copa; as instalações que receberiam as seleções na África do Sul; a contagem regressiva dos dias para o início da copa; retrospectiva de gols marcados em copas anteriores; apresentação das cidades sedes dos jogos do mundial; figurinhas do álbum oficial da Copa de 20 l 0; discussão sobre a convocação do jogador Neymar para integrar a seleção brasileira; apresentação das feras do mundial; os países participantes; entre outros.

Compondo as demais categorias das reportagens apresentadas tivemos: vôlei; atletismo; disputas automobilísticas; esportes radicais; basquete; esporte na mídia; recordes; natação; corrida aérea; boxe; futsal; nado sincronizado; hipismo; beisebol; ginástica artística; ciclismo; judô; paraolimpíadas; handebol; rali; tênis e Educação Física escolar.

Diante do exposto, percebemos uma grande variedade de informações nas reportagens coletadas, especialmente no que concernem as modalidades esportivas. Entretanto, o futebol ganha a dianteira e destaca-se como o mais citado.

Frente a isso, questionamos: e o agendamento para a Copa do Mundo de Futebol de 2014 aconteceu durante as gravações dos telejornais Esporte Fantástico e Esporte Espetacular no mês de abril? Verifica-se inicialmente que não, visto que não foi obtida nenhuma reportagem que fizesse referência direta ao megaevento que delimitamos. Entretanto, foi a partir dessa "ausência" de agendamento que promovemos algumas reflexões sobre a relação da mídia com os esportes.

Afinal, o que aconteceu com o agendamento para a Copa de 20 I 4? Ou será que não aconteceu? Certamente não apresentaremos uma resposta conclusiva para o caso, mas consideraremos algumas hipóteses para refletir e compreender as causas dessa ausência.

Primeiramente, se não obtivemos reportagens sobre a Copa do Mundo de $20 \mid 4$ nas edições analisadas é porque outras tiveram destaque. Na edição jornalística, para se tornar notícia, as informações são selecionadas com base em critérios previamente estabelecidos.

Segundo Sousa (2006, p. 2), a seleção da notícia no jornalismo esportivo, como em qualquer produto jornalístico, é:

Um processo norteado pelos critérios de noticiabilidade universais à atividade de produção e transformação de acontecimentos em fatos notáveis. Também no noticiário esportivo, tem mais chance de se tornar notícia o que é factual, que desperta o interesse do público, que atinge o maior número de pessoas, que seja inusitado ou curioso, que seja novidade e que apresente bons personagens. 
A temática da Copa do Mundo de Futebol de 2014 certamente se enquadra em muitos dos critérios de noticiabilidade apresentados, entretanto não foi selecionada no período analisado pelos "fabricantes" das reportagens. Esse processo de seleção e decisão do que deve ser notícia é bastante discutido na teoria do Gatekeeper de David White.

"O conceito de Gatekeeper (guardião do portão, em inglês) se refere a uma pessoa que deve tomar uma série de decisões". Assim,

Na teoria de White, o processo de seleção de notícias é concebido como uma série de escolhas, onde um fluxo de notícias deve passar por uma série de "portões" (os famosos Gates), que são momentos de decisão em relação aos quais o gatekeeper (o jornalista) tem de decidir se vai escolher ou não esta notícia, deixá-la passar ou não (BAIBICH, 2007, p. 18-19).

Na conclusão de White, os critérios de publicação ou não das notícias são arbitrários e subjetivos, e provocam uma distorção involuntária dos fatos. Portanto, tomando como base os resultados apresentados, onde o futebol se destaca como o mais citado, verificamos que este se enquadra em muitos dos critérios de seleção apresentados e por isso teria passado pelos "portões" das edições jornalísticas.

A "Copa de 2014" também faz parte da temática do futebol e, no entanto, não foi citada/agendada nas 79 reportagens classificadas nesse grupo, certamente ficando guardada para outros momentos. Como "justificativa" para esse fato, elencamos com base nas categorias de reportagens mais citadas algumas hipóteses.

Nas discussões teóricas realizadas expusemos que a mídia adota critérios de noticiabilidade para construção e transmissão de reportagens, sendo o processo de escolha algo "subjetivo". Assim, durante o período da pesquisa, certamente a temática da Copa de 2014 não atingiu os critérios exigidos, cedendo espaço para outras temáticas.

Esse espaço foi ocupado majoritariamente pelas categorias: Santos, "a sensação do momento", o "arrasa quarteirões do instante", pelo ótimo desempenho da equipe e de seus jogadores no campeonato paulista que se realizava, no período da pesquisa, em suas fases finais; Copa do Mundo de Futebol de 2010, pela importância e proximidade do evento, que iniciaria no dia I I de junho do referido ano; Escândalos, Polêmicas e Fraudes, pelo interesse do público na vida dos esportistas, pelas denúncias, entre outros.

Portanto, ilustramos como exemplo estas três categorias para que possamos pensar o não agendamento no mês de abril de 2010 para a Copa de Futebol de 2014 nos telejornais esportivos Esporte Fantástico e Esporte Espetacular. Compreendemos que estas categorias atingiram os critérios de noticiabilidade exigidos para o momento. No entanto, aqui hipotetizamos: as 79 reportagens sobre o futebol não se configurariam como agendamento para a Copa de 20। 4? 
Fazendo analogia a este fato podemos citar o exemplo da política. Em outubro de 2010 acompanhamos a disputa do pleito eleitoral nas esferas estaduais e federais, no entanto, no período que antecedeu a realização desse evento, foram apresentadas reportagens sobre personagens políticos que possivelmente iriam concorrer a essa disputa, sem fazer referência a ela, (in)conscientemente era realizado o processo de agendamento para esse pleito, mas não de forma direta.

Assim, da mesma forma que na política, isto pode ocorrer no esporte, especialmente no evento debatido neste trabalho, a Copa do Mundo de Futebol de 20 I 4. O fato de não termos obtido nenhuma reportagem direta sobre esse evento não nos permite afirmar que não houve agendamento, visto que de forma implícita e (in)consciente este pode ter acontecido no período e espaço investigado.

O que procuramos com essa análise é chamar a atenção do leitor para o fato de que embora não tenhamos obtido nenhuma reportagem sobre a Copa de 20 I 4 nos telejornais e tempo investigado, o agendamento pode sim ter acontecido de forma imperceptível para os telespectadores através da discussão dos inúmeros assuntos sobre futebol, e prioritariamente sobre a Copa de 2010 , em que muitas das situações discutidas envolveram, também, a realização da Copa de 2014 no Brasil.

Estamos diante de uma das maiores estratégias utilizadas pela mídia para a comercialização dos seus produtos e aceitação das suas informações, ou seja, para veicular ideias e incutir sentidos, símbolos e significados aos seus receptores não precisa fazê-los de forma explícita, isto pode ser realizado de modo imperceptível, o que gera um estado de falsa consciência e impede que os questionamentos surjam.

\section{CONSIDERAÇÕES FINAIS}

Diante do exposto, percebemos que a relação estabelecida entre o esporte e a mídia, mais especificamente, entre o esporte espetáculo de competições e a mídia televisiva, é intensamente recortada por interesses dos que detém o poder da produção das informações que serão mediadas. Este jogo de interesses acaba por veicular verdades sobre as práticas esportivas, que são consumidas sem maiores reflexões pelos telespectadores.

Os telespectadores, como peças centrais do processo de mediação, necessitam despertar suas reflexões para as informações mediadas. A televisão em suas transmissões não oportuniza o desenvolvimento autônomo e criativo dos receptores, para ela é mais vantajoso o consumo irrefletido. Na relação com o esporte esta segue a mesma lógica, tornando-se ainda mais intensa pela capacidade de suscitar emoções que as práticas esportivas possuem.

Pensando isto, consideramos oportuno compreender quais interesses estão postos na apropriação midiática desses fenômenos, especialmente pelo atual cenário 
brasileiro que conquistou o direito de sediar esses dois eventos, a Copa do Mundo de Futebol em 2014 e as Olimpíadas em 2016.

Neste estudo buscamos contribuir para esta compreensão, a partir da investigação do processo de agendamento midiático para a Copa de Futebol de 2014. A não ocorrência de forma direta nos permitiu especular, com base nas teorias apontadas, no material coletado e analisado, elementos que apontam para diferentes estratégias utilizadas pela mídia na seleção e veiculação das informações, bem como da forma implícita que muitas informações são mediadas.

Compreendemos que, para além das reflexões teóricas acerca da relação estabelecida entre os esportes e a mídia, é necessário o desenvolvimento de propostas que possam integrar a teoria e a prática, ampliando os espaços de formação crítica para recepção das informações midiáticas sobre os assuntos esportivos. Dentre estes, apontamos o espaço escolar, especialmente o contexto das aulas de Educação Física, como local importante para refletir sobre esta relação, de forma a atingirmos um contingente maior de pessoas, ultrapassando os espaços acadêmicos para se fazer presente nos espaços sociais mais amplos.

Portanto, é necessário atenção às estratégias e interesses da mídia na veiculação de suas informações, particularmente quando relacionado aos assuntos esportivos. Para isso, defendemos uma formação crítica e emancipada de professores e alunos nos espaços de ensino e que possa proporcionar posicionamentos conscientes e autônomos quando for abordada a temática do esporte e sua relação com a mídia, ou seja, o esporte midiático, principalmente no contexto das aulas de Educação Física.

\section{Pages from a Diary: the Media Agenda-Setting for the Cup 2014}

ABSTRACT: Brazilian scenario, where the country won the right to host the two biggest events of sports competition, the soccer World Cup in 2014 and the Olympics in 2016, the relationship between sports and media will surely be intensified, and thus we must be careful not just be passive consumers of media information. The search for understanding about this relationship, this study aimed to reflect on the media agenda-setting for the soccer World Cup in 2014, so, the research investigated the newscasts Fantastic Sports (Rede Record) and Sports Spectacular (Rede Globo) during the month of April 2010.

KEYWORDS: Media; World Cup 2014; Schedule; Physical Education.

\section{Páginas de un diario: programacíon de los medios de comunicacíon de la Copa 2014}

RESUMEN: Escenario brasileño, cuando el país ganó el derecho a organizar los dos eventos más importantes de la competición deportiva, la Copa Mundial de Fútbol en 2014 y los Juegos 
Olímpicos en 2016, la relación con la prensa deportiva seguramente se intensificará, y por lo tanto debemos tener cuidado no sólo ser consumidores pasivos de información multimedia.

Por lo tanto, la búsqueda de la comprensión de esta relación, este estudio tuvo como objetivo reflexionar sobre el calendario de los medios de comunicación para la Copa Mundial de Fútbol 2014, tanto para el trabajo investigó los noticieros Deporte Fantastico (Rede Record) y deporte espectacular (Rede Globo) durante el mes de abril de 2010.

PALABRAS CLAVES: Medios de comunicación; Copa del Mundo 2014; agendamiento; Educación Física.

\section{REFERÊNCIAS}

ALVES JÚNIOR, D. A relação mídia-esporte: um estudo das mensagens esportiva na televisão e seus efeitos na prática da Educação Física escolar, na percepção do professor. 2008. Dissertação (Mestrado) - Universidade de Brasília, 2008.

BAIBICH, A. M. À sombra do futebol: um estudo sobre a presença do esporte amador em jornais diários de Porto Alegre. 2007. Trabalho de Conclusão de Curso. Universidade Federal do Rio Grande do Sul, Porto Alegre, 2007.

BETTI, M. A Janela de vidro: esporte, televisão e Educação Física. 1997. 279 f. Tese (Doutorado em Educação) - Faculdade de Educação, Universidade Estadual de Campinas, Campinas, 1997.

BITENCOURT, F. G. Esboço sobre algumas implicações do futebol e da copa do mundo para o Brasil: identidades e ritos de autoridade. Revista Brasileira de Ciências do Esporte, Campinas, v. 30, n. 3, p. 173-189, maio 2009.

BRACHT, V. Sociologia crítica do esporte: uma introdução. 3. ed. ljuí: Ed. da Unijuí, 2009.

COSTA, S. R. M. Nação, comunidade imaginada pela mídia? o futebol-espetáculo e as identidades nacionais. In: ENCONTRO NACIONAL DE ESTUDOS MULTIDISCIPLINARES E CULTURA, 3., 2007, Salvador. Anais... Bahia, 2007.

GASTALDO, E. "O país do futebol" mediatizado: mídia e copa do mundo no Brasil. Sociologias, Porto Alegre, ano II, n. 22, p. 352-369, jul./dez. 2009.

. Pátria, chuteiras e propaganda: o brasileiro na publicidade da Copa do Mundo. São Paulo: Annablume; São Leopoldo: Ed. da Unisinos, 2002.

MARCONDES FILHO, C. Midiacriticism ou dilema do espetáculo de massas. In: PRADO, J. L. A. (Org.). Crítica das práticas midiáticas: da sociedade de massa às ciberculturas. São Paulo: Hacker, 2002.

MEZZAROBA, C.; PIRES, G. L. O agendamento esportivo como objeto de pesquisa da Educação Física e como (nova) possibilidade no trato com os conhecimentos da Educação 
Física Escolar. In: CONGRESO ARGENTINO, 8., 2009, La Plata; LATINOAMERICANO DE EDUCACION FÍSICA Y CIENCIAS, 3., 2009, La Plata. Anais... La Plata, 2009.

MEZZAROBA, C. Esporte e lazer na perspectiva da indústria cultural: aproximações preliminares. Esporte e Sociedade, Campinas, ano 4, n. I I, mar.jul. 2009.

PIRES, G. L. Mídia, esporte e ilusão. In: FÓRUM INTERNACIONAL DE ESPORTE E LAZER (FIESLA), 2006, Rio de Janeiro. Anais... Rio de Janeiro, 2006.

ROCHA, E.; AUCAR, B. Fantástico, o show da vida: televisão, convergência e consumo. ALCEU, v. II, n. 22, p. 43-60, jan./jun. 201।.

SEABRA, G. F. Pesquisa científica: o método em questão. Brasília: Ed. da Universidade de Brasília, 200I.

SILVA, C. L.; MARCHI JÚNIOR, W. Comunicação televisiva: reflexões e considerações sobre o telejornalismo esportivo. Revista Eletrônica Rázon y Palabra, n. 69, 2009.

SOUZA, L. C. S. Cobertura esportiva na televisão: critérios de noticiabilidade na interface entre jornalismo e entretenimento. In: ENCONTRO NACIONAL DE PESQUISADORES EM JORNALISMO, 4., 2006, Porto Alegre. Anais... Porto Alegre, 2006.

Recebido em: II jun. 2012 Aprovado em: II jun. 2013

Endereço para correspondência: Hudson Pablo de Oliveira Bezerra Rua Antônio Ribeiro de Bessa, n. 158 $\mathrm{COHAB}$ - Portalegre - RN - Brasil 